\title{
The Research and Countermeasures for Ecological Economic Sustainable Development for Zhejiang Province
}

\author{
Tian Tian \\ Department of Management \\ University of Zhejiang Shuren \\ Hangzhou, China \\ tian_tian111@126.com
}

\author{
Yin Lu \\ Department of Biological and Environmental Engineering \\ University of Zhejiang Shuren \\ Hangzhou, China \\ luyin_zjsru@aliyun.com
}

\begin{abstract}
Development of ecological economy is the inevitable requirement to achieve sustainable economic development, but also the development trend of the global economy. This paper introduced the basic concept of the ecological economy and the need for the development of eco-economy. Taking Zhejiang Province as an example, this paper analyzed the countermeasures of province's eco-economy to achieve sustainable development, from three aspects which are the establishment of the system of ecological economic development evaluation mechanism, building the legal guarantee system of ecological civilization and construction to effectively promote the practice in Zhejiang. As the first batch of pilot provinces of building an ecological province, the implementation of eco-economic sustainable development in Zhejiang Province is significant, and it will also play an important reference for other provinces and cities.
\end{abstract}

Keywords-ecological economy; sustainable development; Zhejiang province

\section{INTRODUCTION}

Developing ecological economy is the only way to achieve sustainable development. The ideology of sustainable developed in the mid-1980s, which was from the people worries on the Earth's ecological environment deterioration. In the early 20th century, the British urban planning sociologist Edward Howard put forward on the prototype thought of the modern ecological city, which was named Garden City Theory ${ }^{[1]}$. In the research on human and BioNET plan initiated by UNESCO in 1971, the former Soviet Union urban ecologist Chomsky first proposed the concept of Ecocity ${ }^{[2]}$. United Nations Conference on Environment and Development put forward the strategy of sustainable development for the first time in June 1992, and the sustainable development concept become the consensus of the world soon. At present a large number of foreign cities around the world, such as the city Erlangen in German, Washington D.C. and Cleveland, have carried out series of studies of urban ecosystems and ecological city construction practice. These Western developed countries have higher starting points and tend to solve the sustainable development issues step by step from the resource regeneration, new energy, and ecological compensation mechanism, which have achieved good results ${ }^{[3]}$. In March 1994, China promulgated the "China Agenda 21", which is the world's first national action plan of "Agenda 21".In 1995,the former State Environmental Protection Agency of China decided to carry out pilot work on ecological demonstration zones in some regions, and to develop a "national ecological demonstration zones Plan".

As the first batch of the pilot building an ecological province, Zhejiang province has made comprehensive progresses on the province's economic rapid, healthy and social undertakings coordinated development through unremitting efforts after the first, and the second phase (2003 to 2010), and also environmental conditions remain the forefront of the country ${ }^{[4]}$. The 12th of Zhejiang Province in 2011 embodied more clear and specific on this idea. And the Five-Year Plan proposed the implementation of the "double eight" strategy, "innovative province" strategy and "enriching people" strategy for the overall strategy, which will develop ecological economy, focus on the construction of ecological culture, and constantly optimize the ecological environment, and strive to improve the institutional mechanisms. Therefore, the construction of ecological civilization is a major strategic decision for Zhejiang facing the resource and environmental pressure. And it is also a good opportunity for economic development mode shift to a low-carbon economy and sustainable development.

\section{CONCEPT OF ECOLOGICAL ECONOMIC}

The ecological economic is a complex ecosystem which contains social, economic and natural. And it is a scientific concept of development and a new economic development model. Ecological economic means within the carrying capacity of the ecosystem, it will use the principle of ecological economics and systems engineering approach to change production and consumption patterns, tap the potential of all available resources, and develop an eco-efficient industry. And at the same time, it will build the reasonable institutional, social harmonious cultural as well as ecological health, and landscape suitable environment.

Following the 1992 International Conference on Environment and Development in Rio de Janeiro, most developed countries have made the ecological construction as one of the main macro-control objectives. As a result, ecoindustrial development presents a market-oriented and growing. 
At present, the ecological economic development presents four trends, which are as followed:

(1) Ecological economic model led by market and corporate behavior. Enterprises increasingly become the subject of ecoindustry.

(2)The ecological industry has continued to grow and expanded to the primary secondary and tertiary industries from a single environmental protection industry.

(3) The high-tech pilot the eco-industrial.

(4)Green consumption has become a new fashion ${ }^{[5]}$.

\section{THE NECESSITY OF THE DEVELOPMENT OF ECOLOGICAL ECONOMIC}

After China's accession to the WTO, the primary, secondary and tertiary industry is facing new opportunities and challenges. Especially after the 2008 financial crisis, there is no doubt that we should take a number of contingency measures ${ }^{[6]}$. One important point is to change the comprehensive catch-up strategy to the comparative advantage strategy. For Zhejiang Province, it means we should make in-depth analysis of the comparative advantage over the province to play out their characteristics. Therefore, taking the road of sustainable development of ecological economy, establishing an ecological province is in line with the need for strategic adjustment of economic structure, and accord with the relatively good ecological and environmental advantages. It is also an important measure to help the Zhejiang SME be out of the woods.

For the primary industry, the structure of China's agriculture and rural economy has entered a new stage of strategic adjustment. Zhejiang Province is not an agricultural province in the traditional sense, but there are still some advantages in some economic crops, Such as Changshan citrus, the Tangxi loquat, and Huangyan tangerine, etc. The adjustment is in order to adapt to the market for agricultural diversification, and to the demand for high-quality. And it is also to fundamentally improve the overall quality and efficiency of agriculture and the rural economy in Zhejiang Province to increase farmers' income.

For the second industry, the development of eco-friendly enterprise is the requirements of national industrial policy. China has taken a variety of means for the polluting industrial enterprises off, such as shutting down, discharge restrictions. We should take the chance to vigorously develop the environmental protection industry, and promote cleaner production technologies. And it is easy to get the support of the state and to enhance the international competitiveness. Meanwhile, Zhejiang has a number of small and medium enterprises, the vast majority of which are facing restructuring and upgrading because high pollution and high energy consumption enterprises do not meet the needs of sustainable development, and will eventually be phased out ${ }^{[7]}$. Therefore, to create an ecological economy as an opportunity to establish the economic model of sustainable development is an urgent need to achieve the transformation and upgrading of SMEs in Zhejiang Province.
The tertiary industry has been to occupy an important position in the Zhejiang Economic and it should therefore be to maintain the advantage ${ }^{[8]}$. Taking tourist industry as an example, if we do not take the protection of the environment in the first place throughout the tourism development, ultimately the tourism industry falters. Zhejiang is a big province of tourism resources. Protecting and optimizing the ecological environment is the lifeline of tourism development. In addition, the emerging service industry boomed in Zhejiang bring a new impetus to Zhejiang's economy. The future development of the emerging service industry should be based on the ecological and economic requirements of sustainable development, and take the road of coordinated development of ecological and environmental protection, and service industries, which in order to promote the further development of the service industry.

\section{THE COUNTERMEASURES FOR ECOLOGICAL AND ECONOMIC SUSTAINABLE DEVELOPMENT FOR ZHEJIANG PROVINCE}

\section{A. Establish the comprehensive system of ecological and economic development evaluation mechanisms}

Only by establishing a more systematic and improve the evaluation mechanism, it is more reasonable and effective to promote the ecological province of Zhejiang sustainable development. From the values and ideals of view, this evaluation mechanism changes the previous single economic measure mode, and emphasizes the unity of the ecological, economic and social benefits. For index selection, it is divided into two levels of formal and informal institutions. The formal system includes four aspects which are the system of environmental protection, rational use of resources system, pollution control systems, and material recycling system. And the informal system includes people's day-to-day economic behavior, the level of social development, human settlements environment quality level metrics. The index weight calculation is based on three levels which are the target layer A (eco-city construction evaluation), the evaluation factors layer B (Economic Development B1, the Environmental Protection $\mathrm{B} 2$, social progress B3), and the index factor layer C (selected specific indicators). The three levels are scored separately and given the relative importance of sorting to determine the weights of all levels and the method of calculation. And then they are calculated step by step using weighted sum method.

\section{B. Building the legal guarantee system of ecological civilization construction}

In accordance with the principle of attaching equal importance of pollution control and ecological protection ${ }^{[9]}$, we could improve the legislation, on the basis of the implementation of existing laws, regulations, rules and policies according to the actual needs of Zhejiang Province. And we should focus on the development of local laws and regulations, and government regulations of which environmental protection and construction, promoting the development of circular economy, promoting clean production, and strengthening the construction project environmental protection as the main content. This means that we need to strengthen the 
administrative law enforcement, and the establishment of a sound enforcement responsibility system. And we also need to strengthen the supervision of the implementation of construction project, resource development and utilization and ecological environmental protection laws, regulations and policy. Meanwhile, we need to strengthen legal supervision of the National People's Congress and CPPCC democratic supervision, emphasis on and play the role of the media and the public social supervision ${ }^{[10]}$.

\section{Construction to effectively promote the practice in Zhejiang}

1) Accelerate the transformation of economic growth mode, and promote the transformation and upgrading of industrial clusters

Traditional extensive economic growth mode violated the essence of sustainable development, and due to the scarcity of resources, this growth will come to an end ${ }^{[11]}$. However, intensive mode of economic growth is to improve the technical level, thereby enhancing total factor productivity to achieve economic growth. Starting from the actual situation in Zhejiang Province, we have to raise the rate of total factor productivity as a fundamental starting point, to accelerate the transformation of economic growth mode, promote industrial restructuring and upgrading.

Individual enterprises must cooperate with other companies within the cluster, in order to establish internal symbiotic mechanism-based supply chain collaborative management system, to enhance the competitiveness and expansion of the industrial clusters to promote industrial clusters rapid and sustainable development ${ }^{[12]}$. And relied on supply chain management, it will promote the development of industrial clusters and competitive advantage. Cooperation plays gathering economic effects to make up for the SMEs diseconomies of scale defects. And competition will promote technology innovation, and enhance product quality and industrial level, which is to provide an innovative incentive for the majority of small and medium enterprises. Zhejiang has a number of small and medium enterprises. Through collaborative management of cluster supply chain system, it will help the SMEs compete with large enterprises, and also promote a beneficial economic cycle ${ }^{[13]}$.

2) High quality to build environmentally friendly ecoagriculture

First, we could adhere to the planning guidance to encourage local conditions to develop ecological agriculture. We encourage the use of agricultural waste energy and resources, and the development of ecological agriculture industry around. Second, we could adhere to scientific and technological innovation, to achieve the breakthrough of ecoagricultural technology. Rely on science and technology, we plan to organize and implement the good features of ecological agriculture industry, green certification of agricultural products, the safety of agricultural production and other key projects. We should focus on the construction of demonstrative new rural areas, focusing on the construction of a number of ecoagriculture demonstration zones, to promote the rapid and healthy development of eco-agriculture in Zhejiang Province.

\section{3) Developing ecological services industry}

We need to promote and optimize the various types of services industry, from various fields and aspects to strengthen environmental protection, in order to create favorable social service system of ecological civilization construction. Therefore, we could develop modern service industry, transform the traditional flow of commerce services sector and reduce the flow of commerce services sector usage of disposable consumer goods. At the same time, we should strengthen the treatment of waste gas, waste water, solid waste and commercial waste, and improve recycling levels of commercial waste and waste materials. In addition, we should control the growth rate of the high water consumption and high energy-consuming, such as bath industry, the car wash industry, dyeing industry, to establish management system of commerce and services industry which adapts to water supply capacity.

4) Developing circular economy, focusing on ecotechnological innovation

"The guiding ideology of the circular economy is the concept of sustainable human development" ${ }^{114]}$. However, in Zhejiang Province, the current situation is that the development of circular economy, science and technology is relatively slow. Thus, Zhejiang Province should comprehensively deepen the construction of circular economy as a pilot province. We should implement the circular economy "991" plan of action, which is led by the Government, and gradually use of renewable resources in terms of policy, funding, infrastructure and other technology. We could guide renewable resources market development, strengthen ecological construction of industrial parks, promote clean production, and actively foster energy conservation and environmental protection industry. By enhancing the horizontal cooperation between the different industries, we could promote recycling of resources, and promote the development of circular economy to achieve new results.

\section{CONCLUSION}

Reform and opening up 30 years, China's urbanization rate has reached $46.6 \%$ from $12 \%$ of the beginning of the founding. At the same time, the accompanied city ecological problems increasingly serious and urgently needs to be solved. The goal of establishing an ecological province is not just to improve the city environmental quality, and more importantly, to make the whole economy sustainable development. As southeast coastal economically developed provinces, Zhejiang Province should be more based on the eco-city concept of comprehensive, coordinated and sustainable development, in order to strengthen the construction of ecological environment, to improve the ecological environment quality as the fundamental starting point, and to pursue efficient, high-quality, zero-waste or less-waste production and consumption patterns. Therefore, Zhejiang should do effort to change patterns of development and achieve the ecological development of the provinces and cities. It will not only be as a model and benchmark for the role of Zhejiang sustainable economic development in the future serve, but also be a reference on the development of the country's urban ecological. 


\section{ACKNOWLEDGMENT}

Project Source: Soft science research project of the Science and Technology Department of Zhejiang Province (2012C25104).

\section{REFERENCES}

[1] H. Zhaoyi, and Y. Dongyuan, "The theoretical approach of the ecological city,” City Planning Review, vol. 25, pp. 35-46, January 2001.

[2] F. Vester, and A. Von Hesler, Ecology and planning in metropolitan areas sensitivity model. Berlin: Federal Enviromental Agency, 1980.

[3] Z. Yunyun, "Research and thinking of building an ecological province," Economic Research Guide, vol. 16, pp. 151-152, August 2009.

[4] Z. Jun, "Actively explore new path of scientific development and promote ecological civilization-Summary of Zhejiang to promote the construction of ecological province ,” Today Zhejiang, vol.11, pp. 12-16, November 2010.

[5] Q. Xiaohong, "Considerations about the Sustainable Development of Ecological Economy in Changzhi City," Scitech Information Development \& Economy, vol. 20, pp. 120-122, October 2010.

[6] X. Jun, W. Xinhong, and W. Yuhon, "Problems and path of cities' ecological development-Taking Zhengzhou City as an example," Resource Development \& Market, vol. 27, pp. 528-530, June 2011.
[7] H. T. Odum, Environmental Accounting: Emergy and Decision Making. New York: John Wily \& Sons, 1995.

[8] S. Ulgiati, H. T. Odum, and S. Bastinanoni, "Emergy use, environmental loading and sustainability: An emergy analysis of Italy,” Ecological Modeling, vol. 73, pp. 200-268, June 1994.

[9] M. T. Brown, and T. McClanahan, "Emergy analysis perspectives of Thailand and Mekong river dam proposals,” Ecological Modeling, vol. 91, pp. 100-130, November 1996.

[10] D. F. Whitfield, Emergy Basis for Urban Land Use Patterns in Jacksonville, Florida. Dept. Of Landscape Architecture, Univ of Florida, Gainesville, 1994.

[11] L. Zhijie, C. Kelong, Z. Zhiqiang, S. Maoxin, and Z. Fei, "Study on sustainable development of urban ecologlcal - economic system in $\mathrm{Xi}$ Ning city based on emergy analysis,” Journal of Arid Land Resources and Environment, vol. 25, pp. 7-10, January 2011.

[12] Z. Zhengfeng, “The development of the agricultural cycle Model," Research of Agricultural Modernization, vol. 29, pp. 61-64, January 2008.

[13] W. Boqi, and L. Jingui, "Developping vigorously the circular agriculture for the construction of ecological province,” Fujian Agricultural Science and Technology, vol. 7, pp. 93-96, July 2012.

[14] D. Liqiong, L. Heping, and Q. Weishan, "Assessment of sustainability in eco-economic system in Shanxi Province based on energy analysis," Bulletin of Soil and Water Conservation, vol. 31, pp. 175-179. June 2011. 